presencia del hijo tuvieron un riesgo $56 \%$ más alto de ser hospitalizados por una infección respiratoria que los de madres que fumaban pero que no lo hacían en la misma habitación donde estaba el bebé. El no fumar nunca en la misma habitación redujo en $70,6 \%$ el riesgo pronosticado cuando la madre a veces o por habitud fumaba en la misma habitación.

Las infecciones respiratorias observadas fueron de las vías respiratorias altas en 121 niños y de las bajas en 258. El aumento del riesgo en niños de madres que fumaban fue menor en el caso de las infecciones respiratorias superiores que en de las vías inferiores, pero los hijos de madres que fumaban en la misma habitación mostraron un riesgo aproximadamente igual de ambos tipos de infecciones.

En conclusión, el riesgo de infecciones respiratorias agudas de cualquier tipo es $50 \%$ mayor en hijos menores de un año de madres que fuman, pero si la madre observa buenos hábitos de higiene tabáquica y nunca fuma en la misma habitación donde se encuentra el niño, el riesgo se reduce de un modo significativo. Si estas asociaciones son de tipo causal, las madres que no pueden abandonar el hábito de fumar pueden, por lo menos, reducir la susceptibilidad de sus hijos a infecciones respiratorias agudas peligrosas procurando nunca fumar en la misma habitación. (Blizzard L et al. Parental smoking and infant respiratory infection: how important is not smoking in the same room with the baby? Am J Public Health 2003;93(3):482-494.)

\section{Las caries dentales en los niños y la exposición al humo de tabaco}

Las caries dentales son la enfermedad crónica más común en los niños, principalmente en aquellos que viven en condiciones de pobreza, aunque las razones no están bien definidas. Se trata de una enfermedad infecciosa que se debe a la colonización del dientes por Streptococcus mutans, bacteria que produce ácido láctico por fermentación de carbohidratos, con el resultado de que el ácido corroe la superficie dental. El motivo por el cual algunos niños son más susceptibles que otros no son del todo claras. Algunos autores opinan que la exposición a humo de tabaco en el ambiente, la cual se observa con mayor frecuencia en niños de clase socioeconómica baja, podría ser un factor de riesgo de caries dental. Esta creencia se basa en estudios anteriores en que se ha demostrado que el humo de tabaco se asocia con periodontitis en adultos y también en otras investigaciones que apuntan hacia un posible papel causal del humo de tabaco en la formación de caries. Para explorar esta hipótesis, un grupo de investigadores estadounidenses examinó datos transversales, obtenidos de la Third National Health and Nutrition Examination Survey (NHANES III) estadounidense, sobre 3873 niños entre las edades de 4 y 11 años a quienes se les había sometido a un examen dental y a mediciones de concentraciones de cotinina sérica, que fueron la principal variable independiente de interés. Se tomó como indicio de tabaquismo pasivo una concentración de esta última sustancia $\geq 0,2$ pero $<10 \mathrm{ng} / \mathrm{mL}$, siendo este punto de corte el que separa aproximadamente a la población fumadora en la que tiene una exposición al humo de tabaco por encima y por debajo de la mediana.

De los niños estudiados, 3531 tuvieron por lo menos un diente deciduo cariado y 2930 por lo menos un diente permanente con caries. En general, $53,1 \%$ de estos niños (2 057) tuvieron concentraciones de cotinina sérica compatible con la exposición al humo de tabaco; 46,7\% (1 809) tuvieron superficies dentales deterioradas o calzadas en dientes primarios, y $26,2 \%$ (1 015$)$ tuvieron superficies dentales deterioradas o calzadas en dientes permanentes. El análisis de dos variables mostró una asociación estadísticamente significativa entre las concentraciones séricas de cotinina y las caries en superficies dentales (razón de posibilidades $[R P]=$ 2,1; IC95\%: 1,5 a 2,9), y también entre dichas concentraciones y la presencia de calzas en los dientes $(\mathrm{RP}=1,4$; IC95\%: 1,1 a 1,8). Se observó, además, una asociación directa significativa entre la pobreza y la poca escolaridad y el riesgo de caries o dientes calzados. El ser de raza negra o de extracción mexicano-estadounidense también se asoció significativamente con un mayor número de superficies dentales cariadas pero con un menor número de dientes calzados. En el caso de la dentadura primaria, se observó una tendencia a un riesgo incrementado en relación directa con la concentración de cotinina sérica. Asimismo, esta concentración resultó ser un factor predictivo significativo del riesgo de caries en dientes primarios.

En el estudio no se detectó ninguna asociación significativa entre las concentraciones de cotinina y las caries en la dentadura permanente. No se puede descartar la posibilidad de que dichas concentraciones sean un simple marcador de alguna otra causa de caries dental, como podría ser, por ejemplo, la presencia de malas prácticas de higiene en hogares donde los padres fuman. El estudio también posee otras limitaciones, entre ellas la edad avanzada de los niños estudiados y su naturaleza transversal, cuando lo ideal sería saber las concentraciones de cotinina que tenían los niños antes de cumplir un año. No obstante, es la primera vez que se estudia en niños estadounidenses la asociación entre la exposición pasiva al humo de tabaco y el riesgo de caries dental. Es necesario efectuar más estudios que exploren esta 
asociación para determinar si hay una relación causal. (Aligne CA et al. Association of pediatric dental caries with passive smoking. JAMA 2003; 289(10):1258-1269.)

Posibles marcadores de la susceptibilidad al cáncer colorrectal

Recientemente un grupo de investigadores de la Universidad Johns Hopkins publicó los resultados de una investigación preliminar en 172 sujetos según la cual pronto podría haber un análisis de sangre para identificar a las personas que presentan un riesgo elevado de sufrir cáncer colorrectal. La prueba es capaz de detectar una alteración genética en personas susceptibles, y un resultado positivo significa que la persona afectada debe someterse al tamizaje con colonoscopia con mayor frecuencia que las personas que carecen de dicha alteración. El marcador en cuestión es un defecto en el gen que codifica la proteína conocida por "factor de crecimiento similar a la insulina II" (IGF 2, por insulin-like growth factor 2) y está presente en alrededor de $30 \%$ de las personas con cáncer colorrectal y en solamente $10 \%$ de las personas sin la enfermedad.

La mutación tuvo una frecuencia cinco veces mayor en las personas con antecedentes familiares de cáncer de colon y tres veces mayor en las que habían tenido pólipos anteriormente. En pacientes con cáncer de colon, la alteración genética ocurre 22 veces más que en personas sin antecedentes familiares o personales de la enfermedad.
En otro estudio independiente, investigadores del Centro de Investigación Hutchinson/MRC en Cambridge, Massachussets, Estados Unidos realizaron un estudio en un pequeño grupo de personas, algunas de las cuáles tenían cáncer colorrectal y otras no. La prueba, que se realiza con una muestra de heces, fue capaz de identificar a 37 de un total de 40 personas con cáncer confirmado por colonoscopia, 9 de las cuales estaban en etapa muy temprana de la enfermedad, así como a personas que no tenían la neoplasia. Aunque estos resultados demuestran que la prueba tiene una gran capacidad para discriminar entre personas con y sin cáncer de colon o recto, es demasiado temprano para saber si tiene utilidad para el tamizaje de la población en general.

La prueba se basa en la detección de la llamada proteína de mantenimiento de microcromosomas 2 (minichromosome maintenance protein 2, o MCM 2), que facilita la replicación del $\mathrm{ADN}$, y se encuentra exclusivamente en la superficie de células colorrectales cancerosas, nunca en las células normales. Su ubicuidad en las heces de personas afectadas permite efectuar una prueba de detección que no es invasora y que es mucho más cómoda que la colonoscopia o sigmoidoscopia y más fiable que el guayaco en heces, ya que no todos los cánceres de colon o recto sangran de forma continua. (Cui $\mathrm{H}$ et al. Loss of IGF2 imprinting: a potential marker of colorectal cancer risk. Science 2003 Mar 14;299(5613): 1753-1755; Davies RJ et al. Analysis of minimichrosome maintenance problems. Lancet 2002;359(9321): 1917-1919.)

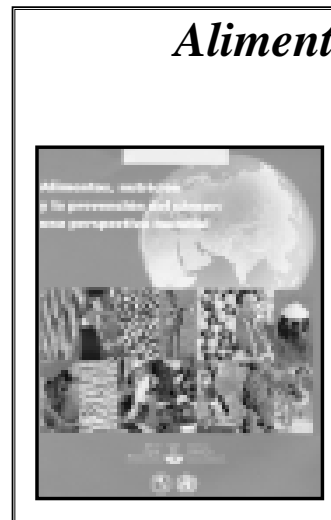
Este libro se refiere explícitamente a la prevención primaria del cáncer desde una
perspectiva mundial. Se subrayan los aspectos de la alimentación y la nutrición que probablemente reduzcan el riesgo de cáncer, y se les da la importancia que merecen a los que podrían incrementar ese riesgo.

Este libro sólo se puede adquirir en formato electrónico por medio de Ingenta Select: * Visite el sitio: http://www.ingentaselect.com

* Seleccione "Pan American Health Organization" en la opción Browse by publishers * Seleccione cualquiera de los títulos ofrecidos 